\title{
Impacts of robotic arm use on individuals with upper extremity disabilities: A scoping review
}

(c) CAOT 2019

Article reuse guidelines:

sagepub.com/journals-permissions

www.cjotrce.com

@SAGE

\author{
Examen de la portée des impacts de l'utilisation de bras robotisés \\ auprès des personnes ayant des incapacités aux membres \\ supérieurs
}

\section{Maude Beaudoin, Josiane Lettre, François Routhier, Philippe S. Archambault, Martin Lemay, and Isabelle Gélinas}

Key words: Activities of daily living; Assistive devices; Disabled persons; Occupational therapy; Robotics.

Mots clés : Activités de la vie quotidienne; Aides techniques; Ergothérapie; Personnes handicapées; Robotique.

\begin{abstract}
Background. Robotic arms may help users perform various activities. Even though robotic arms are commercially available, their impacts are still poorly understood. Purpose. This scoping review aimed to identify the potential impacts of using robotic arms for individuals with upper-extremity disabilities and appraise the scientific quality of the selected studies. Method. A search for studies published between 1970 and 2016 was conducted in PubMed, Embase, Compendex, and Scopus. The Canadian Model of Occupational Performance and Engagement was used to classify activities in which impacts were evaluated. The quality of each study was rated using McMaster University's critical review form for quantitative studies. Findings. Thirty-six studies were reviewed, which evaluated self-care (2I), productivity (33), and leisure (8). The short-term impacts were more commonly documented than long-term impacts. The impacts identified were mostly positive. The studies' mean quality score was $8.8 / 15$. Implications. Additional studies with more rigorous conditions are needed to produce higher-quality scientific evidence of the long-term impacts of robotic arm use.
\end{abstract}

\begin{abstract}
Abrégé
Description. Les bras robotisés peuvent aider les utilisateurs à réaliser diverses activités. Bien que les bras robotisés soient disponibles sur le marché, leurs impacts sont encore peu connus. But. Cet examen de la portée avait pour but d'identifier les impacts potentiels de l'utilisation de bras robotisés auprès des personnes ayant des incapacités aux membres supérieurs et d'évaluer la qualité scientifique des études sélectionnées. Méthodologie. Une recherche a été effectuée en vue de repérer des études publiées entre 1970 et 2016 dans PubMed, Embase, Compendex et Scopus. Le Modèle canadien du rendement et de l'engagement occupationnels a été utilisé pour classer les activités dans lesquelles des impacts étaient évalués. La qualité de chaque étude a été déterminée à l'aide du formulaire d'évaluation critique des études quantitatives de la McMaster University. Résultats. Trente-six études évaluant les soins personnels (2I), la productivité (33) et les loisirs (8) ont été examinées. Les impacts à court terme étaient documentés plus souvent que les impacts à long terme. Dans l'ensemble, les impacts identifiés étaient positifs. La moyenne des scores de qualité des études était de $8,8 / 15$. Conséquences. Davantage d'études devront être menées dans des conditions plus rigoureuses afin de produire des données probantes de plus grande qualité sur les impacts à long terme de l'utilisation de bras robotisés.
\end{abstract}

Funding: This work was supported by a summer scholarship obtained by Maude Beaudoin from the Faculty of Medicine of Laval University, and François Routhier is a Fonds de recherche du Québec-Santé (FRSQ) Research Scholar (junior I) (Grant No. 27088).

Corresponding author: François Routhier, 525 Boulevard Wilfrid-Hamel, Québec, QC, GIM 2S8, Canada. Telephone: 4I8-529-9|4I ext. 6256. E-mail: Francois.Routhier@rea.ulaval.ca 
I ndividuals with upper-extremity disabilities face multiple, daily challenges stemming from the interaction between the person, the environment, and the person's desired occupations. Occupational therapists can analyze this interaction with the Canadian Model of Occupational Performance and Engagement (CMOP-E; Polatajko, Townsend, \& Craik, 2013). Changes in one of the three components of this model, namely, the person, the environment, or the occupation, have an impact on the other components and consequently on the person's occupational performance and engagement. The social, institutional, and physical environments include elements that may help overcome some of the difficulties encountered by individuals with upper-extremity disabilities. The use of assistive devices is one such element as such devices can help users in their independent performance of daily living activities and improve their participation (Parvey, Warren, \& Allen-Collinson, 2015). The field of assistive technology devices is constantly growing and encompasses a wide array of advanced technologies, such as assistive robots. Robotic arms are a type of compensatory assistive robot designed to increase the independence of individuals with upper-extremity disabilities in physical tasks (Brose et al., 2010). They can be mounted either on a desk or on a motorized wheelchair (Brose et al., 2010); thus they are not worn by individuals but rather are completely external assistive devices controlled by the user through an interface. They support the user in the realization of different activities, such as opening cabinet doors, eating, working, and so on (Brose et al., 2010).

Many models of robotic arms have been developed and tested on an experimental basis, but only few have been commercialized. To our knowledge, two commercial models currently prevail on the market: the iARM (Exact Dynamics, Didam, Netherlands; see Figure 1) and the JACO (Kinova Robotics, Montréal, Canada; see Figure 2). Both robotic arms are designed to be mounted on a user's motorized wheelchair, have 6 degrees of freedom and can reach objects at a distance of $90 \mathrm{~cm}$ (Exact Dynamics, 2012; Kinova Robotics, 2016). The iARM has two fingers and can be controlled through multiple types of interfaces (Exact Dynamics, 2016). As for the JACO robotic arm, two grippers have been developed: one with three fingers and another with two fingers (Kinova Robotics, 2016). The JACO can be operated with the same control system as that of the wheelchair (Kinova Robotics, 2016). Using a robotic arm could have major impacts by enabling individuals with upperextremity disabilities to increase their participation in different tasks or activities that require manipulation (Brose et al., 2010). This is especially important since many daily activities involve the use of the hands and arms. Matsumoto, Nishida, Motomura, and Okawa (2011) found that $43 \%$ of all actions done by healthy people include lifting an object. The majority of the other activities observed also required the use of an upper limb: putting things down, preparing complex meals, manipulating and carrying objects in the hands, cleaning a kitchen counter, and so on (Matsumoto et al., 2011). Multiple medical conditions can negatively affect the use of upper extremities. Individuals living with muscular dystrophy, spinal cord injury,

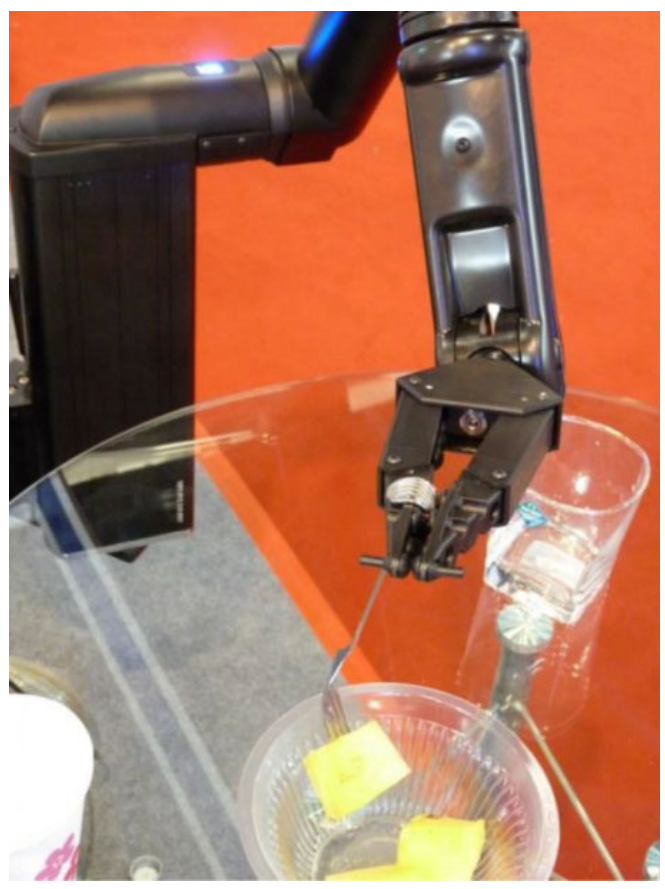

Figure I. The iARM. Photo courtesy of Exact Dynamics, Didam, Netherlands (exactdynamics.nl).

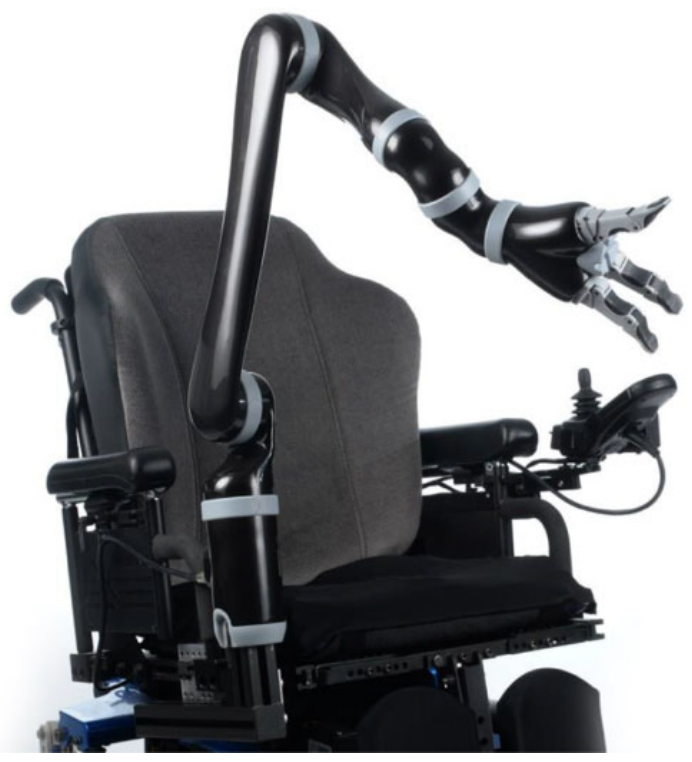

Figure 2. The JACO robotic arm. Photo courtesy of Kinova Robotics, Montreal, Canada (kinovarobotics.com).

spinal muscular atrophy, multiple sclerosis, amyotrophic lateral sclerosis, cerebral palsy, rheumatoid arthritis, postpolio syndrome, locked-in syndrome, and other severe motor disabilities could benefit from using a robotic arm (Laffont et al., 2009).

A literature review on robotic arms, published in 2013 by Chung, Wang, and Cooper, focused on identifying the assessment tools used in the literature to assess the performance of robotic arms in performing activities of daily living (ADLs) in 
the context of user interfaces development. These authors identified modifications to the many common assessment tools that would render them appropriate for the evaluation of robotic arms' performance. In particular, they suggested standardizing the ADLs used to assess the performance of human-robot interaction; using the International Classification of Functioning, Disability and Health (ICF) codes and domains to develop these assessments; and using valid and reliable assessments that are appropriate when considering the constraints of robotic arms.

Yet, the impacts of using a robotic arm by individuals with upper-extremity disabilities remain poorly understood. It is important for clinical practice to understand how individuals actually use robotic arms in their daily activities and what types of tasks they are able to perform. Therefore, the main goal of our study was to identify current knowledge about the potential impacts of robotic arm use by individuals with upper-extremity disabilities. In addition, we wanted to know what gaps need to be filled to provide stronger evidence on the impacts of the use of these assistive devices. Specifically, objectives of this study were (a) to identify the short- and long-term impacts of using robotic arms for individuals with upper-extremity disabilities available in the literature and (b) to appraise the scientific quality of the selected studies. To achieve these objectives, we sought to identify available evidence in the field of assistive technology device outcomes research that documents "the changes that are produced by AT [assistive technology] in the lives of users and their environments" (Fuhrer, Jutai, Scherer, $\&$ DeRuyter, 2003, p. 1244). In our study, these changes have been identified as "impacts" and have been framed within the Consortium for Assistive Technology Outcomes Research (CATOR) taxonomy for assistive technology device outcomes (Jutai, Fuhrer, Demers, Scherer, \& DeRuyter, 2005). We considered as impacts all outcomes included in any of the three outcome vantages of the CATOR taxonomy, namely, effectiveness (body functions, activities and participation, environmental factors, user longevity), social significance (caregiving, cost, residential care placement, service utilization, device utilization), and subjective well-being (psychological functioning, quality of life, satisfaction). Thus, our study complements the results of Chung and colleagues (2013) by identifying the outcomes of robotic arms.

\section{Method}

We conducted a scoping review on the impacts of the use of robotic arms by individuals with upper-extremity disabilities. This type of study is designed to examine the current state of research on a particular topic (extent, range, and nature of activity) and to identify gaps that need to be addressed by new research (Arksey \& O'Malley, 2005). Since we are interested in a broad research question, a scoping review was appropriate, as it allows the inclusion of a variety of study designs and research findings (Arksey \& O'Malley, 2005). The present study goes beyond the traditional scoping review in that it also rates the
Table I

Search Terms Applied to Databases

\begin{tabular}{|c|c|}
\hline Database & Search terms \\
\hline PubMed & $\begin{array}{l}\text { ((“Robotics”[Mesh]) OR (“Bionics”[Mesh]) } \\
\text { OR (“Automation”[Mesh])) AND } \\
\text { ((“Disabled Persons”[Mesh]) OR (“Self- } \\
\text { Help Devices”[Mesh]) OR } \\
\text { (“Rehabilitation”[Mesh]))) NOT } \\
\text { ((exoskeleton*) OR (prosthe*) OR } \\
\text { (surgical))) }\end{array}$ \\
\hline Embase & $\begin{array}{l}\text { ((('robotics'/exp) AND (('disabled person'/ } \\
\text { exp) OR ('rehabilitation equipment'/exp) } \\
\text { OR ('rehabilitation'/exp))) NOT } \\
\text { ((exoskeleton*) OR (prosthe*) OR } \\
\text { (surgical))) }\end{array}$ \\
\hline Compendex & $\begin{array}{l}(((\{\text { Robotics }\} \text { WN CV }) \text { OR }(\{\text { Robotic } \\
\quad \text { arms }\} \text { WN CV) OR (\{Manipulators }\} \\
\text { WN CV) OR (\{Multipurpose robots }\} \\
\text { WN CV OR (\{Robots }\} \text { WN CV })) \text { AND } \\
((\{\text { Human rehabilitation equipment }\} \\
\text { WN CV) OR }(\{\text { Independent living } \\
\text { systems }\} \text { WN CV) OR (\{Patient } \\
\text { rehabilitation }\} \text { WN CV }))) \text { NOT } \\
((\text { exoskeleton*) OR (prosthe*) OR } \\
(\text { surgical })))\end{array}$ \\
\hline $\begin{array}{l}\text { PubMed, Embase, } \\
\text { Compendex, Scopus }\end{array}$ & $\begin{array}{l}(((\text { robotic*) AND (assistive) AND } \\
((\text { rehabilitation) OR (disab*) OR } \\
\left.\left.\quad\left(\text { wheelchair }^{*}\right)\right)\right)\end{array}$ \\
\hline
\end{tabular}

scientific quality of the selected studies (Arksey \& O'Malley, 2005). We believe such a rating is needed to afford a critical look at the findings in the literature and to identify potential research gaps.

\section{Inclusion and Exclusion Criteria}

Only scientific studies containing original results and conference presentations were considered. The studies had to describe a clinical study evaluating the short- or long-term impacts of robotic arm use. We excluded complete collections of conference proceedings, systematic reviews of literature, and scoping reviews. Also excluded were studies focusing on assistive devices or robots that do not have the function of a robotic arm (robots with a unique function, e.g., feeder; robots used in surgery; mobile robots; humanoid or social robots; arm supports; exoskeletons; orthoses and prostheses) as well as robots that are used for training (assistive robotics for the lower extremities and training robots for upper-extremity rehabilitation). Finally, studies on the development of a robotic arm or control interfaces were also excluded.

\section{Literature Search}

The literature review was conducted in July 2014 in PubMed, Embase, Compendex, and Scopus. It was updated in June 2016, without any new results. The search terms shown in Table 1 
were chosen after consultation between two of the authors and were applied to the different databases.

The search was limited to studies published in English or French between 1970 and 2016. The choice of this time frame was based on the review of the literature on robotic arms mentioned previously, since their authors had identified the years 1970 to 2013 as the most significant in the development and study of this assistive device (Chung et al., 2013). First, titles and abstracts were scanned for relevance. The studies identified as relevant were read in full, and a final choice was made of which studies to include in the analysis. The reference lists of the selected papers were also scanned for additional relevant studies. One additional study that did not emerge from the search of the databases or reference lists was added since the authors knew of its existence and it met the inclusion criteria. The study selection process was completed in one step by one of the authors. In the event of uncertainty, two other authors were consulted to make the final decision on the inclusion or exclusion of a study in the analysis.

\section{Extraction of the Data}

An in-house grid was created to extract the following information from each selected study: the objective of the study, the type of robotic arm evaluated, the participants' characteristics, the research design, the variables measured and the measurement tools used, and finally, the main results. One of the authors identified each of these parameters after a careful reading of the studies.

\section{Conceptual Model}

In this study, the focus was on the interaction between a person with upper-extremity disabilities (person), a robotic arm (element of the physical environment), and the activities realized (occupation). In each reviewed study, we identified the activities that were used to assess the impacts of using the robotic arm on the user and classified these according to the three areas of occupation of the CMOP-E, namely, self-care, productivity, and leisure (Polatajko et al., 2013). Self-care encompasses ADLs, functional mobility, and community life. Productivity covers a range of activities aimed at a person's social and economic fulfilment. In the case of an adult, this includes work and instrumental activities of daily living (IADLs). For children, schoolwork and play are considered. Finally, leisure comprises activities done for recreation and fun. Activities were classified following the CMOP-E by the same author who selected the studies and extracted the data.

\section{Scientific Quality of the Studies}

The scientific quality of the selected studies was analyzed using McMaster University's critical review form for quantitative studies (Law et al., 1998). The 15 criteria of this review form are (a) study purpose was stated clearly, (b) relevant background literature was reviewed, (c) research design was

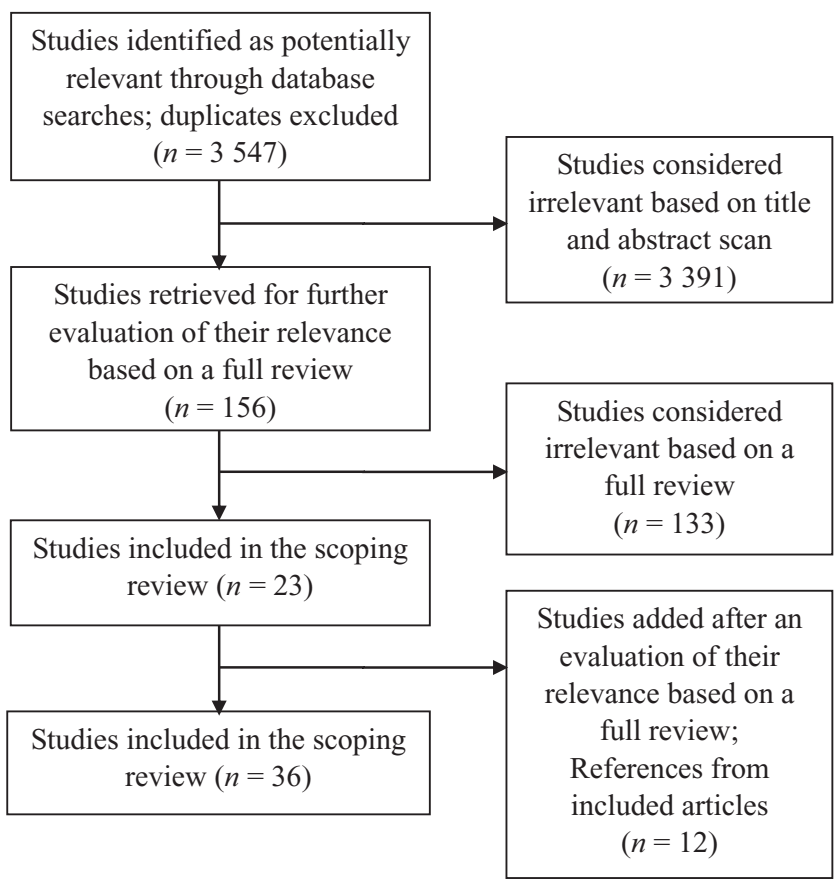

Figure 3. Study selection process flowchart.

appropriate, (d) sample was described in adequate detail, (e) sample size was justified, (f) outcome measures were reliable, (g) outcome measures were valid, (h) intervention was described in adequate detail, (i) contamination was avoided, (j) co-intervention was avoided, (k) results were reported in terms of statistical significance, (l) analysis method used was appropriate, (m) clinical significance of findings was reported, (n) number of dropouts was reported, and (o) conclusions were appropriate to study findings (Alexandratos, Barnett, \& Thomas, 2012). This form was not originally designed to assign quality scores, but an adaptation was proposed by Alexandratos et al. (2012). This adaptation was used to rate the quality of each of the selected studies with a score out of 15 points. Each criterion was scored on a 0 -or- 1 scale. A total score of 0 to 5,6 to 10 , or 11 to 15 was considered as low, average, or high quality, respectively. Two authors rated the studies individually. A consensus was reached for all the criteria for each of the studies.

\section{Findings}

From the database searches, 36 studies were identified that met the inclusion criteria. The study selection process is summarized in Figure 3.

\section{Description of the Selected Studies}

All the selected studies were published between 1983 and 2014. Five (14\%) were published between 1980 and 1989, $12(33 \%)$ between 1990 and 1999, seven (19\%) between 2000 and 2009, and 12 (33\%) between 2010 and 2016. A total 
Table 2

Classification of Articles According to the Areas of Occupation of the Canadian Model of Occupational Performance and Engagement Evaluated With Robotic Arms

\begin{tabular}{|c|c|c|c|c|c|c|c|c|}
\hline \multirow[b]{2}{*}{ Article } & \multicolumn{3}{|c|}{ Self-care } & \multicolumn{4}{|c|}{ Productivity } & \multirow[b]{2}{*}{ Leisure } \\
\hline & ADLs & Mobility & Community life & IADLs & Work & School & Play & \\
\hline Anderson (1990) & & & & & $\mathrm{x}$ & & & \\
\hline Bach, Zeelenberg, \& Winer, (1990) & $\mathrm{x}$ & & & $x$ & & & & $\mathrm{x}$ \\
\hline Birch et al. (1996) & & & & & $\mathrm{x}$ & & & \\
\hline Busnel et al. (1999) & $\mathrm{x}$ & & & & $\mathrm{x}$ & & & $\mathrm{x}$ \\
\hline Cammoun, Detriche, Lauture, \& Lesigne (1993) & $\mathrm{x}$ & & & $\mathrm{x}$ & & & & $\mathrm{x}$ \\
\hline Chaves, Koontz, Garber, Cooper, \& Williams (2003) & $\mathrm{x}$ & & & $x$ & & & & \\
\hline Clark (2013) & $\mathrm{x}$ & & & $x$ & & $x$ & & $\mathrm{x}$ \\
\hline Cook, Howery, Gu, \& Meng (2000) & & & & & & & $\mathrm{x}$ & \\
\hline Cook, Bentz, Harbottle, Lynch, \& Miller (2005) & & & & & & $x$ & $\mathrm{x}$ & \\
\hline Cook, Liu, \& Hoseit (1990) & & & & & & & $\mathrm{x}$ & \\
\hline Danielsson \& Holmberg (1994) & & & & & $x$ & & & \\
\hline Eberhardt, Osborne, \& Rahman (2000) & & & & & & $x$ & & \\
\hline Gelderblom et al. (200I) & $\mathrm{x}$ & & & $x$ & & & & \\
\hline Grigorescu, Lüth, Fragkopoulos, Cyriacks, \& Gräser (2012) & & & & $x$ & & & & \\
\hline Hall, Glass, Hammel, Leifer, \& Perkash (1987) & $\mathrm{x}$ & & & $x$ & & & & \\
\hline Hammel et al. (1989) & $\mathrm{x}$ & & & $x$ & & & & \\
\hline Hammel, Van der Loos, \& Perkash (1992) & $\mathrm{x}$ & & & $x$ & $x$ & & & \\
\hline Hillman (1987) & $\mathrm{x}$ & & & $x$ & & & & \\
\hline Jardón Gil, De La Peña, Monje, \& Balaguer (201I) & $\mathrm{x}$ & & & & & & & \\
\hline Jardón, Monje, \& Balaguer (20I2) & $\mathrm{x}$ & & & & & & & \\
\hline Kim et al. $(2010)$ & & & & $x$ & & & & \\
\hline Kim et al. (20I2) & & & & $\mathrm{x}$ & & & & \\
\hline Kwee, Quaedackers, Van de Bool, Theeuwen, \& Speth (1999) & $\mathrm{x}$ & & & $x$ & & & & $\mathrm{x}$ \\
\hline Kwee, Quaedackers, Van de Bool, Theeuwen, \& Speth (2002) & $\mathrm{x}$ & & & $x$ & & & & $x$ \\
\hline Kwee et al. (1983) & $\mathrm{x}$ & & & $x$ & & & & \\
\hline Maheu, Archambault, Frappier, \& Routhier (2011) & & & & $x$ & & & & \\
\hline Mahoney (200I) & $\mathrm{x}$ & & & $x$ & & & & \\
\hline Routhier \& Archambault (2010) & & & & $x$ & & & & \\
\hline Routhier et al. (2014) & $\mathrm{x}$ & $\mathrm{x}$ & $x$ & $\mathrm{x}$ & $\mathrm{x}$ & $x$ & & $x$ \\
\hline Seamone \& Schmeisser (1985) & $\mathrm{x}$ & & & $x$ & & & & \\
\hline Topping \& Smith (1999) & $\mathrm{x}$ & & & & & & & $x$ \\
\hline Van der Loos et al. (1990) & $\mathrm{x}$ & & & $x$ & $\mathrm{x}$ & & & \\
\hline Virtanen \& Vapaakoski (1993) & & & & & $\mathrm{x}$ & & & \\
\hline Wakita et al. (2013) & $\mathrm{x}$ & & & $x$ & & & & \\
\hline Wakita, Yoon, \& Yamanobe (20/2) & & & & $x$ & & & & \\
\hline Wang et al. (2013) & & & & $x$ & & & & \\
\hline
\end{tabular}

Note. ADLs = activities of daily living; IADLs = instrumental activities of daily living.

of 27 different robotic arm systems were evaluated. Participants' age varied from a few months to over 80 years. Eighteen studies (50\%) included only adults, four (11\%) involved participants under 18 years of age, and three $(8 \%)$ had various age groups. Age was not provided for 11 studies (31\%). Concerning gender, $76 \%$ of the participants were men and $24 \%$ were women; this information was not available for 14 studies (39\%). Robotic arms were evaluated with populations with various diagnoses. Individuals with spinal cord injury received the most attention, with eight studies (22\%) focusing specifically on this population. Two studies (6\%) included only individuals with muscular dystrophy, while four $(11 \%)$ had only individuals with cerebral palsy. Participants in the other 15 studies (42\%) had various pathologies. Single- and multiple-case studies were the research designs most often used, accounting for 17 (47\%) of the selected studies. Crosssectional studies were the second most common design, with 11 studies (31\%). The other studies had various designs: three $(8 \%)$ were cohort studies, two $(6 \%)$ had pre-/posttest designs, two $(6 \%)$ were case series, and one $(3 \%)$ had a crossover design. Only one study (3\%) reported robotic arm use over several years.

The activities that were used to assess the impacts of using a robotic arm on the user, classified according to the three areas of occupation of the CMOP-E, are presented in Table 2. In 21 studies (58\%), the assessments were associated with self-care. All of these evaluated ADLs while functional mobility and community life were evaluated in only one study (3\%). 
Thirty-three studies (92\%) described assessments related to productivity: 24 (67\%) evaluated IADLs while eight (22\%) examined work situations, three (8\%) focused on play, and four (11\%) focused on school. The assessments in eight studies $(22 \%)$ were related to leisure activities. (See Appendix A at http://journals.sagepub.com/doi/suppl/10.1177/0008417418820878 for a list of the selected studies, their objective, the robotic arm evaluated, the participants' characteristics, the research design, the variables measured, the measurement tools, and the main results).

\section{Impacts of Robotic Arm Use}

The assessments that focused on ADLs and IADLs showed that users are able to successfully accomplish a variety of tasks with a robotic arm (Bach, Zeelenberg, \& Winter, 1990; Chaves, Koontz, Garber, Cooper, \& Williams, 2003; Clark, 2013; Gelderblom et al., 2001; Hammel, Van der Loos, \& Perkash, 1992; Jardón, Gil, De La Peña, Monje, \& Balaguer, 2011; Jardón, Monje, \& Balaguer, 2012; Kim et al., 2012; Kwee, Quaedackers, Van de Bool, Theeuwen, \& Speth, 1999; Maheu, Archambault, Frappier, \& Routhier, 2011; Mahoney, 2001; Routhier \& Archambault, 2010; Van der Loos et al., 1990; Wakita et al., 2013; Wakita, Yoon, \& Yamanobe, 2012; Wang et al., 2013). For example, the use of a robotic arm allowed users to drink (Jardón et al., 2012; Wakita et al., 2013), to eat (Wakita et al., 2013), and to brush their teeth (Jardón et al., 2012). Therefore, many authors concluded that robotic arms have the potential to increase users' independence (Chaves et al., 2003; Clark, 2013; Gelderblom et al., 2001; Hammel et al., 1989; Jardón et al., 2011, 2012; Seamone \& Schmeisser, 1985; Topping \& Smith, 1999). Two studies also looked at the reduction in human assistance that could be achieved by using a robotic arm. It was estimated that the average time per day spent on ADLs and IADLs could be reduced by $1.31 \mathrm{hr}$ (Maheu et al., 2011) to $3 \mathrm{hr}$ (Bach et al., 1990). Concerning users' satisfaction, results of the included studies showed that modifications or improvements in existing robotic arms are needed to better meet their users' needs (Bach et al., 1990; Busnel et al., 1999; Cammoun, Detriche, Lauture, \& Lesigne, 1993; Clark, 2013; Grigorescu, Lüth, Fragkopoulos, Cyriacks, \& Gräser, 2012; Hall, Glass, Hammel, Leifer, \& Perkash, 1987; Hammel et al., 1989, 1992; Hillman, 1987; Jardón et al., 2011, 2012; Kim et al., 2010, 2012; Kwee et al., 1983, 1999; Kwee, Quaedackers, Van De Bool, Theeuwen, \& Speth, 2002; Seamone \& Schmeisser, 1985; Topping \& Smith, 1999; Wakita et al., 2013; Wang et al., 2013). For example, in a study evaluating the ASIBOT robot, participants suggested several changes to make it more useful, such as reducing its size, incorporating a voice recognition system, adding tasks, and improving safety conditions (Jardón et al., 2011).

In leisure situations, the results were similar. Using a robotic arm in leisure activities made it possible to successfully perform a variety of activities (Bach et al., 1990; Clark, 2013; Hillman, 1987; Kwee et al., 1999). For example, the robotic arm allowed users to access leisure and sports activities (Clark, 2013), to draw, or to play with a doll (Kwee et al., 1999). Users were moderately satisfied but considered that improvements were still needed (Busnel et al., 1999; Cammoun et al., 1993; Routhier et al., 2014). Suggested improvements concerned, for instance, the aesthetics of the system, the installation process, and the development of more appropriate user interfaces (Cammoun et al., 1993).

When evaluated in a work situation, robotic arms enabled users to execute job-related activities, such as using a computer or a phone (Hammel et al., 1992; Van der Loos et al., 1990; Virtanen \& Vapaakoski, 1993). Some mentioned that improvements should be made to facilitate the use and integration of this assistive device in their workplace (Busnel et al., 1999; Danielsson \& Holmberg, 1994; Hammel et al., 1992; Virtanen \& Vapaakoski, 1993). An example of an improvement suggested was increasing the speed of execution of a task (Danielsson \& Holmberg, 1994). Results concerning productivity at work are also available. Two studies compared how long it took to complete a work task with human assistance or independently with a robotic arm (Birch et al., 1996; Van der Loos et al., 1990). They found that task completion time was longer with the robot than when asking a caregiver to assist with the task (Birch et al., 1996; Van der Loos et al., 1990). In other words, productivity with the robotic arm was lower than with human assistance. However, workers with disabilities reportedly asked for less help when they were equipped with this assistive device (Birch et al., 1996; Virtanen \& Vapaakoski, 1993). On the other hand, one study reported that using a robotic arm at work could help users with disabilities attain a level of productivity similar to that of an able-bodied person (Anderson, 1990).

The number of studies on the use of robotic arms by children and youth in school and at play is limited. However, assessments of robotics arms with young children in play situations showed that those with disabilities could activate the device following visual, verbal, or physical prompts depending on the task difficulty (Cook, Howery, Gu, \& Meng, 2000; Cook, Liu, \& Hoseit, 1990). The impacts were mainly related to the school setting, including the finding that students with severe neuromuscular disabilities could perform school projects in a largely independent manner when equipped with a robotic arm (Eberhardt, Osborne, \& Rahman, 2000). According to teachers interviewed by Cook, Bentz, Harbottle, Lynch, and Miller (2005), a robotic arm could foster the development, independence, motivation, and integration of children and youth by enabling them to participate in a wider variety of activities related to academics, such as asking questions, reading, or drawing.

\section{Scientific Quality of the Studies}

The overall mean score for the scientific quality was $8.8 / 15$; therefore, we considered the mean level as average. For selfcare, the mean score for the quality of studies on ADLs was $8.6 / 15$. The quality score for the only study evaluating mobility and community life was $9 / 15$. For productivity, the means for the quality of studies were as follows: IADLs, 8.7/15; work, 9.3/ 
15; school, 9.5/15; and play, 9/15. Finally, the mean for the quality of studies evaluating leisure was $8.4 / 15$. Six of the criteria used to judge the scientific quality of the studies were met least often. The number of participants was justified (criterion [e]) in seven studies (19\%). With respect to the psychometric properties of the measurement tools, three $(8 \%)$ studies mentioned reliability (criterion [f]) and two (6\%), validity (criterion [g]). The criteria on avoiding contamination and co-intervention (criteria [i] and [j], respectively) were not met by any of the studies; in fact, the possibility of these phenomena being present or absent was not discussed. Seven studies (19\%) discussed the statistical significance of the findings (criterion $[\mathrm{k}]$ ).

\section{Discussion}

This scoping review examined the potential impacts of using a robotic arm for individuals with upper-extremity disabilities and rated the quality of the available evidence. The findings point to positive impacts on the performance of some activities and an increase in independence that could result from using this type of assistive device for all the areas of occupation of the CMOP-E. These results imply the possibility of a positive impact on the user's occupational performance and engagement. The activities receiving the most attention in the selected studies were ADLs and IADLs. Therefore, more results are available for these types of activities, and conversely, more research is necessary to better understand the impacts of the use of a robotic arm on work, leisure, school, and play. The impacts documented were mainly short term; only one study identified in our review documented long-term impacts over several years.

The findings on robotic arms were mostly congruent in each domain except in a work setting where findings were contradictory with respect to impacts on productivity. According to some authors, doing a work task with a robot could take more time than asking a caregiver (Birch et al., 1996; Van der Loos et al., 1990), indicating less productivity from the worker. However, in another study, productivity for an assistive-robot user was similar to that of an able-bodied person (Anderson, 1990). In the latter case, however, the method was not clearly defined since the interaction between the robotic arm and user was not described. This makes the results difficult to compare to those of other studies on productivity at work. Consequently, it was not possible to reach any conclusions concerning the impacts of robotic arm use on productivity at work.

When analyzing the studies, varying degrees of user satisfaction were evident. For all categories of activities (self-care, productivity, and leisure), the participants suggested improvements to the robotic arm they had tried. Improving this type of assistive device, including its performance and, therefore, the independence provided, is likely to increase user satisfaction. However, users seemed to like being able to use their robotic arm to do certain activities even if they still required help from a caregiver. This was illustrated by Gelderblom et al. (2001) in their assessment of the MANUS robotic arm. Users of this device reported being more independent and having a better quality of life than nonusers, even though human assistance was still necessary, for example, to prepare the tasks to be accomplished with the robotic arm (Gelderblom et al., 2001).

A wide variety of robotic arms was tested with populations with different ages and diagnoses. This great variability in the literature must be taken into consideration before drawing any conclusions about the impacts of robotic arm use. Each device has its own characteristics and possibilities that can be more or less tailored to what is required to meet the user's specific needs. For example, some impacts that occur with one type of client may not occur with the same robotic arm with a different type of client. The current literature on robotic arms does not allow such distinctions to be made.

It should also be noted that nearly half of the studies (47\%) included in this scoping review involved technology developed prior to 2000. Some of these robotic arms may no longer be in use or may have been improved since the studies describing their assessment were published. Constant and rapid development in the field of assistive technology devices means that new studies must be conducted to update knowledge about the short- and long-term impacts of the latest technology and, most importantly, what is commercialized.

Concerning the scientific quality, the mean for each area of occupation shows that the quality of the studies on work, school, and play was above the overall average. However, these means were computed from a smaller number of studies and were only slightly higher than the overall average ( 0.2 to 0.7 points higher). Therefore, we believe that the quality must be considered as average for all areas of occupation. An average mean scientific quality implies that the studies included in this scoping review present methodological weaknesses.

To evaluate the level of evidence of this scoping review, not only the scientific quality had to be considered but also the designs of the retained studies. We based our analysis on the work of the Oxford Centre for Evidence-Based Medicine. This group developed a table to assess the level of evidence based on the design of a study (Howick et al., n.d.). However, the authors also suggest taking into consideration the scientific quality, since a study with a design that suggests a low level of evidence, an observational study, for instance, but that has a high quality may provide stronger evidence than one with a design that suggests a higher level of evidence but that has a low quality (Howick et al., n.d.). Since most of the studies included in this scoping review had nonexperimental or quasiexperimental designs with an average scientific quality, we considered the level of evidence as low. To increase the level of evidence on the impacts of the use of a robotic arm, studies with stronger designs, such as randomized controlled trial, and of a higher scientific quality are necessary. When studying assistive technology devices, it has been suggested to use a randomized clinical trial whenever possible (Vincent \& Routhier, 2012). However, this type of study may be difficult to set up in the case of robotic arms since the size of the population of interest is limited. Nevertheless, methods must be adjusted to improve quality. Repeated measures before and after receipt of the 
assistive device could provide useful data (Vincent \& Routhier, 2012) and be applicable to the assessment of robotic arms. Articles evaluating assistive technology devices should also employ validated tools to obtain clinically relevant results (Vincent \& Routhier, 2012). Since most selected studies used measurement tools that had not been validated (observations and in-house questionnaires), this explains why their reliability and validity were rarely discussed. This aspect would need to be improved in future studies on robotic arms. In the previous literature review on robotic arms that examined the assessment tools used to assess the user-interface performance, it was suggested to standardize ADL tasks used in assessment and to use valid and reliable functional assessments (Chung et al., 2013). We believe that these suggestions could be applied to the assessment tools that measure the impacts of using a robotic arm on its user. Thus, we support the need to improve design and other methodological consideration while evaluating robotic arms.

\section{Limitations}

When this study took place, the selection of studies, extraction of the data, and classification according to the CMOP-E were all done by one author. Thus, no validation was done in these steps. However, the author who completed the selection, extraction, and classification consulted two of the other authors in case of uncertainty. The exclusion of collections of conference proceedings may have led to the omission of some studies in this review, but we do not think this could change the conclusions of this scoping review, as the goal was to identify current knowledge on a specific topic.

The quality rating reflected the authors' interpretation, which could have altered the scores. However, two authors independently rated the quality of each study. If some of the criteria had been scored differently, the mean score would not have changed much, and the conclusions regarding the quality of the evidence would have been similar.

\section{Conclusion}

Although the level of evidence on the impacts of the use of a robotic arm is considered low, this scoping review pinpointed certain potential impacts of the use of robotic arms for individuals with upper-extremity disabilities. Overall, the main potential impact we documented consisted of an improvement in the performance of some activities and an increase in independence, especially for ADLs and IADLs, over the short term. However, the average scientific quality and wide variability in the activities evaluated, in the robotic arms studied as well as in the results reported, show that further studies with stronger designs and higher scientific quality are needed to draw conclusions concerning the impacts of the use of a robotic arm and especially its long-term impacts. Satisfaction should also be addressed in future studies by improving different features of this assistive device, such as its dimensions (e.g., could be more compact) and the control interfaces (e.g., which could be tailored to the needs and capacities of each user). In addition, in view of the quality scores obtained, the assessment conditions should be improved to establish the short- and long-term impacts of robotic arms with greater scientific rigour (e.g., stronger study designs, larger samples, reliable and valid objective assessments).

\section{Key Messages}

- The scientific quality of the studies in this review is average, and the level of the evidence is low.

- Additional studies with stronger designs and more rigorous assessment conditions are needed to produce reliable evidence on the impacts of robotic arm use for individuals with upper-extremity disabilities.

- Additional studies with quasiexperimental designs (e.g., repeated measures before and after) could be used to produce reliable evidence.

\section{Acknowledgements}

This study was first presented at the Congrès québécois de recherche en adaptation-réadaptation (Boucherville, Canada) in May 2015. In October 2015, it was presented at the 30th annual congress of the French Society of Physical and Rehabilitation Medicine (Montpellier, France), and the presentation's abstract was published in Annals of Physical and Rehabilitation Medicine, Volume 58, Supplement 1, e104 (doi:10.1016/j.rehab.2015.07.239).

\section{Supplemental Material}

Supplemental material for this article is available online.

\section{References}

References marked with an asterisk indicate studies included in the scoping review.

Alexandratos, K., Barnett, F., \& Thomas, Y. (2012). The impact of exercise on the mental health and quality of life of people with severe mental illness: A critical review. British Journal of Occupational Therapy, 7, 48-60. doi:10.4276/030802212X13286281650956

*Anderson, L. (1990). Utilization of a robotic arm to enhance employment opportunities for persons with severe physical disabilities. In Proceedings of the International Conference on Rehabilitation Robotics (pp. 139-143). Wilmington, DE: University of Delaware, AI duPont Institute.

Arksey, H., \& O’Malley, L. (2005). Scoping studies: Towards a methodological framework. International Journal of Social Research Methodology, 8, 19-32. doi:10.1080/13645570320000119616

*Bach, J. R., Zeelenberg, A. P., \& Winter, C. (1990). Wheelchairmounted robot manipulators: Long term use by patients with 
Duchenne muscular dystrophy. American Journal of Physical Medicine \& Rehabilitation, 69, 55-59.

*Birch, G. E., Fengler, M., Gosine, R. G., Schroeder, K., Schroeder, M., \& Johnson, D. L. (1996). An assessment methodology and its application to a robotic vocational assistive device. Technology and Disability, 5, 151-165.

Brose, S. W., Weber, D. J., Salatin, B. A., Grindle, G. G., Wang, H., Vazquez, J. J., \& Cooper, R. A. (2010). The role of assistive robotics in the lives of persons with disability. American Journal of Physical Medicine \& Rehabilitation, 89, 509-521. doi:10.1097/ PHM.0b013e3181cf569b

*Busnel, M., Cammoun, R., Coulon-Lauture, F., Detriche, J. M., Le Claire, G., \& Lesigne, B. (1999). The robotized workstation "MASTER" for users with tetraplegia: Description and evaluation. Journal of Rehabilitation Research \& Development, 36, 217-229.

*Cammoun, R., Detriche, J. M., Lauture, F., \& Lesigne, B. (1993). Clinical evaluation of the "MASTER" robot system and development of a new version. Robotica, 11, 535-539. doi:10.1017/ S026357470001938X

*Chaves, E., Koontz, A. M., Garber, S., Cooper, R. A., \& Williams, A. L. (2003). Clinical evaluation of a wheelchair mounted robotic arm. Paper presented at the RESNA 26th International Annual Conference on Technology and Disability: Research, Design, Practice \& Policy, Atlanta, GA. Retrieved from http://www.resna.org/ sites/default/files/legacy/conference/proceedings/2003/Papers/ sSPWinner/Chaves_SM.htm

Chung, C. S., Wang, H., \& Cooper, R. A. (2013). Functional assessment and performance evaluation for assistive robotic manipulators: Literature review. Journal of Spinal Cord Medicine, 36, 273-289. doi:10.1179/2045772313y.0000000132

*Clark, E. (2013). Utilisation d'un bras robotisé par des personnes ayant un contrôle moteur diminué aux membres supérieurs [Use of a robotic arm by individuals having decreased upper extremity motor control]. Motricité Cérébrale: Réadaptation, Neurologie du Développement, 34, 63-70. doi:10.1016/j.motcer. 2013.03.002

*Cook, A. M., Bentz, B., Harbottle, N., Lynch, C., \& Miller, B. (2005). School-based use of a robotic arm system by children with disabilities. IEEE Transactions on Neural Systems and Rehabilitation Engineering, 13, 452-460. doi:10.1109/tnsre.2005.856075

*Cook, A., Howery, K., Gu, J., \& Meng, M. (2000). Robot enhanced interaction and learning for children with profound physical disabilities. Technology and Disability, 13(1), 1-8.

*Cook, A. M., Liu, K. M., \& Hoseit, P. (1990). Robotic arm use by very young motorically disabled children. Assistive Technology, 2, 51-57. doi:10.1080/10400435.1990.10132150

*Danielsson, C., \& Holmberg, L. (1994). Evaluation of the RAID workstation. In Proceedings of the RESNA'94 Annual Conference (pp. 451-453). Retrieved from https://files.eric.ed.gov/fulltext/ ED431281.pdf

*Eberhardt, S. P., Osborne, J., \& Rahman, T. (2000). Classroom evaluation of the Arlyn Arm robotic workstation. Assistive Technology, 12, 132-143. doi:10.1080/10400435.2000.10132019

Exact Dynamics. (2012). iARM product overview. Retrieved from http://iarmrobot.com/overview.shtml
Exact Dynamics. (2016). iARM. Retrieved from http://www.exactdy namics.nl/site/?page $=$ iarm

Fuhrer, M. J., Jutai, J. W., Scherer, M. J., \& DeRuyter, F. (2003). A framework for the conceptual modelling of assistive technology device outcomes. Disability and Rehabilitation, 25, 1243-1251. doi:10.1080/09638280310001596207

*Gelderblom, G. J., de Witte, L., van Soest, K., Wessels, R., Dijcks, B., van't Hoofd, W, .. van der Pijl, D. (2001). Cost-effectiveness of the MANUS robot manipulator. In M. Mokhtari (Ed.), Integration of assistive technology in the information age (pp. 340-345). Amsterdam, Netherlands: IOS Press.

*Grigorescu, S. M., Lüth, T., Fragkopoulos, C., Cyriacks, M., \& Gräser, A. (2012). A BCI-controlled robotic assistant for quadriplegic people in domestic and professional life. Robotica, 30, 419-431. doi:10.1017/S0263574711000737

*Hall, K., Glass, K., Hammel, J., Leifer, L., \& Perkash, I. (1987). Evaluation of a tabletop robotic aid for quadriplegics. In Proceedings of the 10th Annual Conference on Rehabilitation Technology (pp. 776-777). Washington, DC: RESNA and Association for the Advancement of Rehabilitation Technology.

*Hammel, J., Hall, K., Lees, D., Leifer, L., Van der Loos, M., Perkash, I., \& Crigler, R. (1989). Clinical evaluation of a desktop robotic assistant. Journal of Rehabilitation Research and Development, 26(3), 1-16. Retrieved from http://www.rehab.research.va.gov/ jour/80/1980-89.html

*Hammel, J. M., Van der Loos, H. F. M., \& Perkash, I. (1992). Evaluation of a vocational robot with a quadriplegic employee. Archives of Physical Medicine and Rehabilitation, 73, 683-693.

*Hillman, M. R. (1987). A feasibility study of a robot manipulator for the disabled. Journal of Medical Engineering \& Technology, 11, 160-165. doi:10.3109/03091908709008987

Howick, J., Chalmers, I., Glasziou, P., Greenhalgh, T., Heneghan, C., Liberati, A, ... Thornton, H. (n.d.) Explanation of the 2011 Oxford Centre for Evidence-Based Medicine (OCEBM) levels of evidence: Background document. Retrieved from http://www.cebm.net/ index.aspx?o=5653

*Jardón, A., Gil, Á. M., De La Peña, A. I., Monje, C. A., \& Balaguer, C. (2011). Usability assessment of ASIBOT: A portable robot to aid patients with spinal cord injury. Disability and Rehabilitation: Assistive Technology, 6, 320-330. doi:10.3109/17483107.2010. 528144

*Jardón, A., Monje, C. A., \& Balaguer, C. (2012). Functional evaluation of ASIBOT: A new approach on portable robotic system for disabled people. Applied Bionics and Biomechanics, 9(1), 85-97. doi:10.3233/ABB-2011-0045

Jutai, J. W., Fuhrer, M. J., Demers, L., Scherer, M. J., \& DeRuyter, F. (2005). Toward a taxonomy of assistive technology device outcomes. American Journal of Physical Medicine and Rehabilitation, 84, 294-302. doi:10.1097/01.PHM.0000157313.88732.DC

*Kim, D. J., Hazlett, R., Godfrey, H., Rucks, G., Portee, D., Bricout, J., ... Behal, A. (2010). On the relationship between autonomy, performance, and satisfaction: Lessons from a three-week user study with post-SCI patients using a smart $6 \mathrm{DOF}$ assistive robotic manipulator. In 2010 IEEE International Conference on Robotics and Automation (pp. 217-222). New York, NY: IEEE. 
*Kim, D. J., Hazlett-Knudsen, R., Culver-Godfrey, H., Rucks, G., Cunningham, T., Portée, D, ... Behal, A. (2012). How autonomy impacts performance and satisfaction: Results from a study with spinal cord injured subjects using an assistive robot. IEEE Transactions on Systems, Man, and Cybernetics-Part A: Systems and Humans, 42(1), 2-14. doi:10.1109/TSMCA.2011.2159589

Kinova Robotics. (2016). Products. Retrieved from http://www.kino varobotics.com/assistive-robotics/products/manipulation/

*Kwee, H., Quaedackers, J., Van de Bool, E., Theeuwen, L., \& Speth, L. (1999). POCUS project: Adapting the control of the MANUS manipulator for persons with cerebral palsy. In International Conference on Rehabilitation Robotics (ICORR) (pp. 1-2). Retrieved from http://rehabrobotics.org/icorr1999/papers/papers/kwee.pdf

*Kwee, H., Quaedackers, J., Van De Bool, E., Theeuwen, L., \& Speth, L. (2002). Adapting the control of the MANUS manipulator for persons with cerebral palsy: An exploratory study. Technology and Disability, 14, 31-42.

*Kwee, H. H., Tramblay, M., Barbier, R., Dupeyroux, M., Vinceneux, M. F., Semoulin, P., \& Pannier, S. (1983). First experimentation of the Spartacus Telethesis in a clinical environment. Paraplegia, 21, 275-286. doi:10.1038/sc.1983.47

Laffont, I., Biard, N., Chalubert, G., Delahoche, L., Marhic, M., Boyer, F. C., \& Leroux, C. (2009). Evaluation of a graphic interface to control a robotic grasping arm: A multicenter study. Archives of Physical Medicine and Rehabilitation, 90, 1740-1748. doi:10.1016/j.apmr.2009.05.009

Law, M., Stewart, D., Pollock, N., Letts, L., Bosch, J., \& Westmorland, M. (1998). Critical review form: Quantitative studies. Hamilton, ON: McMaster University.

*Maheu, V., Archambault, P. S, Frappier, J, \& Routhier, F. (2011). Evaluation of the JACO robotic arm: Clinico-economic study for powered wheelchair users with upper-extremity disabilities. In 2011 IEEE International Conference on Rehabilitation Robotics (ICORR) (pp. 1-5). New York, NY: IEEE. doi:10.1109/ICORR. 2011.5975397

*Mahoney, R. M. (2001). The Raptor wheelchair robot system. Assistive Technology Research Series, 9, 135-141.

Matsumoto, Y., Nishida, Y., Motomura, Y., \& Okawa, Y. (2011). A concept of needs-oriented design and evaluation of assistive robots based on ICF. In 2011 IEEE International Conference on Rehabilitation Robotics. New York, NY: IEEE. doi:10.1109/ICORR. 2011.5975437

Parvey, A., Warren, N., \& Allen-Collinson, J. (2015). "It gives me my freedom": Technology and responding to bodily limitations in motor neuron disease. Medical Anthropology, 34, 442-455. doi: 10.1080/01459740.2015.1035782

Polatajko, H. J., Townsend, E. A., \& Craik, J. (2013). The Canadian Model of Occupational Performance and Engagement (CMOP-E). In E. A. Townsend \& H. J. PolatajkoEnabling occupation II: Advancing an occupational therapy vision for

health, well-being, and justice through occupation (2nd ed., p. 23). Ottawa, ON: CAOT Publications ACE.

*Routhier, F., \& Archambault, P. S. (2010). Usability of a joystickcontrolled six degree-of-freedom robotic manipulator. Paper presented at the Rehabilitation Engineering and Assistive Technology Society of North America (RESNA) Annual
Conference, Las Vegas, NV. Retrieved from https://www.res na.org/sites/default/files/legacy/conference/proceedings/2010/ Other/RouthierF.html

*Routhier, F., Archambault, P. S., Cyr, M.-C., Maheu, V., Gélinas, I., \& Lemay, M. (2014). Benefits of JACO robotic arm on independent living and social participation. Paper presented at the Rehabilitation Engineering and Assistive Technology Society of North America (RESNA) Annual Conference, Indianapolis, IN. Retrieved from https:/www.resna.org/sites/default/files/confer ence/2014/Robotics/Routhier.html

*Seamone, W., \& Schmeisser, G. (1985). Early clinical evaluation of a robot arm/worktable system for spinal-cord-injured persons. Journal of Rehabilitation Research and Development, 22, 37-57.

*Topping, M. J., \& Smith, J. K. (1999). The development of Handy 1: A robotic system to assist the severely disabled. Technology and Disability, 10, 95-105.

*Van der Loos, H. F. M., Hammel, J., Lees, D., Chang, D., Perkash, I., \& Leifer, L. (1990). A voice-controlled robot system as a quadriplegic programmer's assistant. Paper presented at the 13th Rehabilitation Engineering and Assistive Technology Society of North America (RESNA) Annual Conference, Washington, DC.

Vincent, C., \& Routhier, F. (2012). Designs in AT research: Usefulness for therapists in clinical practice. Technology and Disability, 24, 49-58. doi:10.3233/TAD-2012-0333

*Virtanen, A., \& Vapaakoski, S. (1993). Robotics helps disabled to work. In Proceedings of IEEE Systems, Man and Cybernetics Conference (pp. 534-538). New York, NY: IEEE. doi:10.1109/ ICSMC.1993.385068

*Wakita, Y., Oyama, E, Yoon, W. K, Tanaka, H., Matsumoto, Y, Blom, A, \& Stuyt, H. (2013). User evaluation of service robotic arms based on ICF through interviews with people with upper-limb disability. In IEEE International Conference on Robotics and Biomimetics (ROBIO) (pp. 1282-1287). New York, NY: IEEE. doi:10. 1109/ROBIO.2013.6739641

*Wakita, Y., Yoon, W.-K, \& Yamanobe, N. (2012). User evaluation to apply the robotic arm RAPUDA for an upper-limb disabilities patient's daily life. In IEEE International Conference on Robotics and Biomimetics (ROBIO) (pp. 1482-1487). New York, NY: IEEE. doi:10.1109/ROBIO.2012.6491178

*Wang, H., Xu, J., Grindle, G., Vazquez, J., Salatin, B., Kelleher, A, ... Cooper, R. A. (2013). Performance evaluation of the Personal Mobility and Manipulation Appliance (PerMMA). Medical Engineering and Physics, 35, 1613-1619. doi:10.1016/j.medengphy. 2013.05.00

\section{Author Biographies}

Maude Beaudoin, MErg, erg., is a master of science student, Département de réadaptation, Université Laval, and Centre for Interdisciplinary Research in Rehabilitation and Social Integration, Centre intégré universitaire de santé et de services sociaux de la Capitale-Nationale, Institut de réadaptation en déficience physique de Québec, Québec, QC, Canada. At the time of this study, M. Beaudoin was a professional master in occupational therapy student, Université Laval, Québec, QC, Canada. 
Josiane Lettre, MSc, MErg, erg., is a research assistant, Centre for Interdisciplinary Research in Rehabilitation and Social Integration, Centre intégré universitaire de santé et de services sociaux de la Capitale-Nationale, Institut de réadaptation en déficience physique de Québec, Québec, QC, Canada.

François Routhier, PhD, PEng., is Associate Professor, Département de réadaptation, Université Laval, and Researcher, Centre For Interdisciplinary Research in Rehabilitation and Social Integration, Centre intégré universitaire de santé et de services sociaux de la Capitale-Nationale, Institut de réadaptation en déficience physique de Québec, Québec, QC, Canada.

Philippe S. Archambault, PhD, erg., is Associate Professor, School of Physical and Occupational Therapy, McGill
University, Montréal, and Researcher, Centre for interdisciplinary research in rehabilitation of the greater Montreal, Centre intégré de santé et de services sociaux de Laval, Jewish Rehabilitation Hospital, Laval, QC, Canada.

Martin Lemay, $\mathrm{PhD}$, is Professor, Département des sciences de l'activité physique, Université du Québec à Montréal, and Researcher, Laboratoire du mouvement et de la cognition, Centre de réadaptation Marie Enfant, Centre hospitalier universitaire Sainte-Justine, Montréal, QC, Canada.

Isabelle Gélinas, $\mathrm{PhD}$, erg., is Associate Professor, School of Physical and Occupational Therapy, McGill University, Montreal, and Researcher, Centre for interdisciplinary research in rehabilitation of the greater Montreal, Centre intégré de santé et de services sociaux de Laval, Jewish Rehabilitation Hospital, Laval, QC, Canada.

\section{Book Review}

Deluliis, Elizabeth D. (20I7). Professionalism across occupational therapy practice. Thorofare, NJ: Slack.

345 pp. US\$56.95. ISBN: 978-I-6309I-09I-4

DOI: $|0|.|77 / 00084| 74|879525|$

The text Professionalism Across Occupational Therapy Practice addresses professionalism in various contexts relevant to the path of an occupational therapist, such as education in university, fieldwork, and clinical practice. This text is primarily aimed at occupational therapy students. With clear learning objectives and concise definitions of key concepts, it would be an interesting reference text for new learners of the subject. The text also presents learning activities to encourage students' reflexivity and to engage them in their process of professionalism development from class to fieldwork to job search.

The text is also applicable to occupational therapy educators and fieldwork supervisors because it provides many concrete pedagogical tools to use to promote professionalism among students, such as pictures of which behaviour to encourage and forms on how to measure professional attitudes. It also provides interesting clinical vignettes that expose unprofessional scenarios that can take place in fieldwork. The author then presents concrete ways to prevent and manage such situations. These tips can be directly applied in practice.

For practising occupational therapists, this text may serve as a resource for ongoing professional development with its tips on how to maintain and improve professionalism over time. A caveat to note is that the book refers on many occasions to the reality of occupational therapy in the United States. Indeed, it deals with the evolution of the profession and rules governing American practice and the functioning of American occupational therapy training programs. In addition, the text is focused predominantly on supporting practice. Readers who wish to deepen their knowledge of the theoretical and conceptual basis of professionalism will remain unfulfilled.

In summary, this text is a practical tool for use in training occupational therapy students. The 15 chapters and 345 pages are written in a dynamic style that will hold the reader's attention. Key features of this text are the many tools and tips it presents to support the development of professionalism among students. I recommend this text to students, educators, and fieldwork supervisors!

Alexandra Lecours, PhD, erg. Département de réadaptation Université Laval, Québec, QC, Canada 